\title{
Leisure-time and transport-related physical activity and the risk of mortality: the CRONICAS Cohort Study
}

Antonio Bernabe-Ortiz, MD, MPH, PhD'; Rodrigo M. Carrillo-Larco, MD ${ }^{1,2}$; Robert H. Gilman, $\mathrm{MD}^{1,3}$; Liam Smeeth, MD, $\mathrm{PhD}^{4}$; William Checkley, MD, $\mathrm{PhD}^{1,5}$; J. Jaime Miranda, MD, MSc, $\mathrm{PhD}^{1,4,6}$.

1. CRONICAS Center of Excellence in Chronic Diseases, Universidad Peruana Cayetano Heredia, Lima, Peru.

2. Department of Epidemiology and Biostatistics, School of Public Health, Imperial College London, London, UK.

3. Department of International Health, Bloomberg School of Public Health, Johns Hopkins University, Baltimore, MD, USA.

4. Faculty of Epidemiology and Population Health, London School of Hygiene and Tropical Medicine, London, UK.

5. Division of Pulmonary and Critical Care, School of Medicine, Johns Hopkins University, Baltimore, MD, USA.

6. Department of Medicine, School of Medicine, Universidad Peruana Cayetano Heredia, Lima, Peru.

Short title:

Physical activity and all-cause mortality

Corresponding author:

Antonio Bernabe-Ortiz, MD, MPH, PhD

CRONICAS Center of Excellence in Chronic Diseases

Universidad Peruana Cayetano Heredia, Lima, Peru

Email: Antonio.Bernabe@upch.pe

\section{Conflict of interest}

The authors declare that no conflict of interest exist.

\section{Funding}

The original CRONICAS Cohort Study was funded in whole with Federal Funds from the United States National Heart, Lung, and Blood Institute, National Institutes of Health, Department of Health and Human Services, under contract No. HHSN268200900033C. RMC-L is funded by a Wellcome Trust International Training Fellowship (214185/Z/18/Z). The funders had no role in the preparation of the manuscript, or the decision to publish. 


\section{ABSTRACT (196 words)}

\section{Background:}

The long-term health association of the leisure-time and transport-related physical activity domains of the International Physical Activity Questionnaire (IPAQ) have not been established in Latin American settings. We aimed to quantify the 7-year all-cause mortality risk associated with levels of leisure-time and transport-related physical activity.

\section{Methods:}

Ongoing prospective cohort study conducted in four sites in Peru. People $\geq 35$ years were randomly selected from the general population in each study site. The exposures were leisure-time and transport-related physical activity (IPAQ) at baseline. The outcome was allcause mortality based on information retrieved from national records. Cox regression and sensitivity analyses were conducted.

\section{Results:}

There were 3601 people (mean age 55.8 years, $51.5 \%$ women). Greater levels of physical activity were associated with lower risk of all-cause mortality, an observation confirmed in sensitivity analyses. Compared to those with low levels of physical activity, leisure-time $(\geq 500$ MET-min/week) and transport-related (500-1499 and $\geq 1500$ MET-min/week) physical activity were associated with $70 \%$ (95\% Cl: $3 \%-90 \%)$, 43\% (95\% Cl: $18 \%-61 \%)$, and $42 \%(95 \% \mathrm{Cl}$ : $8 \%-63 \%)$ lower all-cause mortality, respectively.

\section{Conclusions:}

Greater levels of leisure-time and transport-related physical activity were associated with a strong reduction in the risk of all-cause mortality across different geographical sites.

\section{Keywords:}

Mortality, physical activity, leisure activities, transportation, Peru 


\section{INTRODUCTION}

Physical activity has been associated with important health benefits [1, 2], including, but not limited to a reduction in overweight and obesity rates, and lower risk of cancer as well as mortality [3-5]. Low physical activity continues being an important risk factor contributing to global mortality [6] as the annual rate of physical activity worldwide has not changed during the last decades. As a consequence, the World Health Organization Global Action Plan for the Prevention and Control of Noncommunicable Diseases (NCD) incorporated an aim to reduce modifiable risk factors, including tobacco use, unhealthy diet and physical inactivity, for NCDs and underlying social determinants by creating health-promoting environments [7, 8].

According to the US Department of Health and Human Services, adults should do at least 150 to 300 minutes a week of moderate-intensity, or 75 to 150 minutes a week of vigorousintensity aerobic physical activity or an equivalent combination of moderate- and vigorousintensity aerobic activity [9]. However, existing literature shows high levels of physical inactivity, especially in low- and middle-income countries [10]. In Peru, for example, in a nationally representative sample, low levels of physical activity were reported in $62 \%$ of adults aged 18 to 59 years [11]. Moreover, the baseline assessment of the CRONICAS Cohort Study, conducted in resource-constrained settings with varying degrees or urbanization and altitude, found that physical inactivity was present in $94 \%$ of individuals when measured by the leisure-time domain of the International Physical Activity Questionnaire (IPAQ) [12].

The IPAQ is a widely used tool for assessing and comparing physical activity levels in different populations. Whereas the IPAQ has been validated in different Latin American countries, the application of the full questionnaire has time and resource challenges, as well as limited correlation when contrasted with objective physical activity data [13, 14]. To overcome this, the leisure-time and transport-related domains of the IPAQ has been encouraged in Colombian and Brazilian populations for population-based surveillance and research [15]. Such recommendation may apply to similar populations, including Peru, but the public health implications of using these two IPAQ domains needs to be verified. Moreover, the long-term associations on important outcomes have not been determined yet in Latin American populations. Existing information regarding health benefits of physical activity on all-cause mortality comes mainly from data from high-income countries [16, 17], whereas only two reports were included from resource-constrained settings (Iran and China), and none from Latin America.

As a result, this study aimed to evaluate the association between physical activity levels, assessed by using the leisure-time and transport-related domains of the IPAQ, on all-cause mortality in resource-constrained settings in Peru, using a cohort with 7 years of follow-up.

\section{METHODS}

\section{Study design}

Data from the CRONICAS Cohort Study was used, and its methodological details have been described elsewhere [18]. Briefly, individuals from four Peruvian sites located in three different regions, differing by level of altitude and urbanization, were included. The study sites were Pampas de San Juan de Miraflores, a highly-urbanized, at the sea level setting, in Lima; Puno, a high-altitude region in the Peruvian highlands (3825 meters above sea level), and split into rural and urban settings; and Tumbes, a semiurban low-altitude (sea level), coastal region where rural areas are intermixed with rapidly-growing urban areas. For this 
manuscript, baseline data, collected between 2010 and 2012, and mortality records, retrieved in 2018, were analyzed.

\section{Study participants}

A sex- and age-stratified (35-44, 45-54, 55-64, and 65+ years) random sample was taken for each of the study sites. The sampling frame for this selection was based on information from the most updated census in each site (2010). Individuals were selected by computer from the census list with replacement in case of rejecting participation.

Subjects aged $\geq 35$ years and with full-time residence in the study area were invited to participate. Women who were pregnant, those cognitively incapable of providing informed consent, or those bedridden or with physical disability preventing measurements of blood pressure or anthropometrics were excluded. Only one participant per household was enrolled into the study.

\section{Definition of variables}

Outcome: All cause-mortality was the outcome of interest and was defined by the occurrence of any fatal event between baseline enrollment and any point during follow-up. In 2018, the vital status of participants (dead or alive) was retrieved from national vital registries. For this evaluation, participants were not directly contacted as only vital status and date of death or censoring was required. If a participant had died, the date of death was used for analysis purposes; but if participant was alive, then the date on which the search in the National Registry of Identification and Civil Status (RENIEC in Spanish) database was conducted was considered as the censoring date. The time between baseline assessment and the date of death or censorship was then estimated in years.

Exposure: At the cohort baseline, the leisure-time and transport-related domains of the IPAQ were applied. The decision of using these domains was based on guidance derived from research and evaluation conducted in Latin American countries such as Brazil and Colombia [15]. We used the Spanish version of the IPAQ adapted for similar countries such as Colombia (http://www.ipaq.ki.se/). We defined low and high levels of physical activity for each of these two domains based on specific cutoffs.

In the case of leisure-time physical activity, those with $<600 \mathrm{MET}$-min/week during leisure time were defined as doing none or very little physical activity (i.e., low level), whereas those $\geq 600 \mathrm{MET}$-min/week were considered as doing high level of leisure-time physical activity. Similarly, for transport-related physical activity, low level was defined as reporting not doing any transport-related physical activity and, conversely, any single walk or cycle trip for 10 minutes or more was considered as high transport-related physical activity [19].

In addition, leisure-time physical activity was also split into three groups: $<150$ MET$\mathrm{min} /$ week, between 150 and $499 \mathrm{MET}$-min/week, and $\geq 500 \mathrm{MET}-\mathrm{min} /$ week. This additional definition was based on the distribution of the variables as more than $80 \%$ of study subjects had <150 MET-min/week and to evaluate dose-response. Similarly, transport-related physical activity domain was also split into three categories but with different cut-offs: $<500$ MET-min/week, between 500 and 1499 MET-min/week, and $\geq 1500$ MET-min/week.

Other study variables: Baseline demographic, socioeconomic, and behavioral risk factor variables were included in the analysis as potential confounders of the association of interest. These variables were: sex (male vs. female); age (35-44, 45-54, 55-64, and 65+ years); years of education ( $<7,7-11$, and $12+$ years); socioeconomic position, based on a wealth index using household assets and facilities separately for each study site and then combined into a single variable and presented in tertiles [20]; and study site (highlyurbanized Lima, urban Puno, rural Puno, and semiurban Tumbes). Behavioral risk factors included daily smoking defined as at least one cigarette per day (yes vs. no) [21]; alcohol drinking, based on the consumption of at least 6 drinks of beer or any equivalent beverage once or more per month (high vs. low) [22]; and body mass index, with the traditional cutoffs 
for normal $\left(B M l<25 \mathrm{~kg} / \mathrm{m}^{2}\right)$, overweight $\left(25 \mathrm{~kg} / \mathrm{m}^{2} \leq \mathrm{BMI} \leq 30 \mathrm{~kg} / \mathrm{m}^{2}\right)$, and obesity $(\mathrm{BMI} \geq 30$ $\mathrm{kg} / \mathrm{m}^{2}$ ). In addition, hypertension, defined as systolic blood pressure $\geq 140 \mathrm{~mm} \mathrm{Hg}$, diastolic blood pressure $\geq 90 \mathrm{~mm} \mathrm{Hg}$, or self-report of physician diagnosis or current use of antihypertensive medication (yes vs. no) [23]; total cholesterol levels, defined as normal (total cholesterol $<200 \mathrm{mg} / \mathrm{dL}$ ), high-normal $(200-239 \mathrm{mg} / \mathrm{dL})$, and high ( $\geq 240 \mathrm{mg} / \mathrm{dL})$; and type 2 diabetes status, defined as fasting glucose $\geq 126 \mathrm{mg} / \mathrm{dL}$, or self-report of physician diagnosis or currently receiving antidiabetic drugs [24], were also included.

Total serum cholesterol and plasma glucose were measured after 8-12 hours of fasting. Cholesterol was measured using a Cobas Modular Platform automated analyzer with Roche Diagnostic reagents, whereas glucose was measured using an enzymatic colorimetric method (GOD-PAP, Modular P-E/Roche-Cobas). All samples were analyzed in a single facility, and quality assurance was verified regularly and monitored by Bio-Rad.

\section{Statistical methods}

Analyses were conducted using STATA 16 for Windows (StataCorp, College Station, TX, US). Initially, a description of the sample of participants at baseline was conducted. Median and interquartile range for numerical variables, especially for MET-min/week estimations, and proportions for categorical ones were used. The prevalence of low physical activity levels in each IPAQ domain was estimated with their respective 95\% confidence intervals $(95 \% \mathrm{Cl})$. Comparisons between population characteristics were also pursued using the nonparametric quality-of-median test for numerical variables and the Chi-squared test for categorical ones.

Mortality rates for the overall sample as well as by physical activity levels were estimated by using person-time and incidence rates. These estimates were reported by 1,000 personyears of follow-up. Crude and adjusted Cox proportional hazard models were built to separately assess the association between each of the definitions of leisure-time and transport-related physical activity and all-cause mortality, reporting hazard ratios (HR) and $95 \% \mathrm{Cl}$.

Sensitivity analyses were also pursued by including models and estimations utilizing different cutoffs of physical activity levels. In addition, models were built by excluding deaths occurring within the first two years of follow-up, by excluding hypertension and type 2 diabetes cases at baseline, comparing those who did not report physical activity vs. those reporting any physical activity, and using $500 \mathrm{MET}$-min/week as a cutoff for defining physically active. All these analyses are presented as supplemental material and, for sake of consistency, were done separately for each IPAQ domain.

\section{Ethics}

All participants provided oral informed consent because of high illiteracy rates, mainly in rural areas. The study was approved by the Institutional Review Boards (IRB) at Universidad Peruana Cayetano Heredia (UPCH) and A.B. PRISMA, in Lima, Peru, and the Johns Hopkins University, in Baltimore, US. Follow-up assessment to evaluate vital status of participants in 2018 was approved by the IRB at UPCH.

\section{RESULTS}

\section{Participant characteristics at baseline}

A total of 6872 subjects were contacted, and 4325 were initially enrolled in the cohort. However, 38 had incomplete survey and 686 individuals were not further available. Thus, 3601 participants had information for analysis. Of them, 10 physical activity records were incomplete at baseline. Then, data of 3591 (99.7\%) individuals, mean age 55.8 (SD \pm 12.7 ) years, $51.5 \%$ females, and $1638(45.7 \%)$ had $<7$ years of education, were analyzed. 


\section{Physical activity levels}

Leisure-time physical activity was low in $94.9 \%(95 \% \mathrm{Cl}$ : $94.1 \%-95.5 \%)$ of study subjects, and 2986 (83.2\%; 95\% Cl: 81.9\% - 84.4\%) had levels <150 MET-min/week. In bivariate analyses, low levels of leisure-time physical activity were more frequent among females $(p<0.001)$, older individuals $(p=0.02)$, less educated $(p<0.001)$, those with low socioeconomic position $(p<0.001)$, and those from rural and semiurban settings $(p<0.001)$. However, heavy drinking was associated with greater level of leisure-time physical activity $(p<0.001)$. Details are presented in Table 1 and Supplemental Tables 1 and 2.

On the other hand, only $34.3 \%(95 \% \mathrm{Cl}: 32.7 \%-35.9 \%)$ reported low levels of transportrelated physical activity, and 978 (27.3\%; $95 \%$ Cl: $25.8 \%-28.7 \%)$ had levels <500 MET$\mathrm{min} /$ week. Low levels of transport-related physical activity were more common among females $(p<0.001)$, older individuals $(p<0.001)$, those less educated $(p<0.001)$, among those with low socioeconomic position $(p<0.001)$, in semiurban sites $(p<0.001)$, those with hypertension, and with type 2 diabetes $(\mathrm{p}=0.002)$. See details in Table 2 and Supplemental Tables 1 and 3.

\section{Risk of mortality by physical activity levels}

The vital status of 3321 (92.5\%) subjects was confirmed, with a mean time of follow-up of 7.0 (SD \pm 1.0 ) years, and completing a total of $23,166.4$ person-years. A total of $199(6.0 \%)$ deaths were recorded during the study period, with an all-cause mortality rate of $8.6(95 \%$ $\mathrm{Cl}: 7.5$ - 9.9) per 1,000 person-years.

\section{Leisure-time physical activity and all-cause mortality}

Crude mortality rate was lower among those with high levels of leisure-time physical activity compared to those with low levels, but this association was attenuated in the multivariable model $(\mathrm{HR}=0.45 ; 95 \% \mathrm{Cl}: 0.14-1.41)$. Nevertheless, individuals with $\geq 500 \mathrm{MET}$-min/week of leisure-time physical activity had a reduction of $70 \%$ in the risk of all-cause mortality compared to those with <150 MET-min/week (HR $=0.30 ; 95 \% \mathrm{Cl}: 0.10-0.97)$. See details in Figure 1 and Supplemental Table 4. When sensitivity analyses were conducted, results were consistent with the findings reported here, although some of them were not significant (Supplemental Table 5).

\section{Transport-related physical activity and all-cause mortality}

Regardless of the definition used, higher crude mortality rates were observed among those with low levels of transport-related physical activity. In multivariable model, those with greater levels of transport-related physical activity had, on average, $43 \%$ to $47 \%$ reduction in the risk of all-cause mortality compared to the reference group (Figure 1 and Supplemental Table 4). Similarly, sensitivity analyses yielded results that were consistent with these findings (Supplemental Table 6).

\section{DISCUSSION}

\section{Main findings}

Greater levels of physical activity, assessed using the leisure-time and transport-related IPAQ domains, were associated with a reduction of the risk of all-cause mortality, especially among those with at least $500 \mathrm{MET}-\mathrm{min} /$ week, which is considered a good goal for optimal cardiovascular health [9], including those with cardiovascular conditions [25]. In terms of the magnitude of the association, our estimates are higher than previous studies using selfreported physical activity and already described in the literature [5, 26, 27], which may contribute to a better understanding of the higher burden of NCDs in low-resource settings. Our results also highlight that $95 \%$ of individuals were in the low-level category of leisuretime physical activity, and a third had low level of transport-related physical activity. These 
population patterns point towards major gaps that require attention in the field of health promotion, including the role of physical activity, in order to accrue progress towards the monitoring international indicators including the World Health Organization's (WHO) Global Action Plan for the Prevention and Control of Noncommunicable Diseases [7].

\section{Comparison with previous studies}

A systematic review and meta-analysis examined the association between accelerometerassessed physical activity and all-cause mortality, and concluded that, regardless of intensity, any physical activity was associated with lower risk of mortality with a non-linear dose-response [26]. Similarly, another meta-analysis showed that time spent in daily devicemeasured light-intensity physical activity has been associated with reduced risk of mortality in adults [28]. Previous studies have reported a non-linear dose-response association between physical activity and mortality [5, 26, 27], and such finding is consistent regardless the use of self-reported or device-measured physical activity. However, such dose-response finding was not evident in our results, possibly because of the limited number of events, as only $6 \%$ of participants died during the 7 years of follow-up, or because of the notorious proportion of low levels of physical activity in our population, especially in the case of leisuretime physical activity.

From the leisure-time physical activity perspective, a large pooled 10-year follow-up cohort analysis showed that even low levels of leisure-time physical activity of moderate to vigorous intensity, equivalent to less than half the WHO recommendation, were associated with reduced risk of mortality compared to no such activity [4]. Similarly, in a prospective cohort of participants from 17 different countries, including Argentina, Brazil, Chile and Colombia, reported that higher recreational and non-recreational physical activity were associated with a lower risk of mortality and cardiovascular events among subjects from low-income, middleincome, and high-income countries [29]. However, only pooled data was available and findings for each country were not reported.

Most of the studies focused on transport-related physical activity were based on cycling and walking. A systematic review reported that both cycling and walking reduced the risk of allcause mortality, adjusted for other physical activity domains, defining a cutoff of 675 MET$\mathrm{min} /$ week [27]. Active commuting has been also associated with lower risk of cardiovascular disease, cancer, and all-cause mortality [30]. Thus, our findings using the transport-related IPAQ domain are in line with previous reports regarding this topic and confirm the direction of the association. Importantly, we contribute to the global literature of physical activity and NCDs by providing information from several resource-constrained Latin American settings. In addition, the observed associations with all-cause mortality described in here are much higher than previous studies assessing physical activity through self-report.

\section{Relevance to public health}

Our results suggest that leisure-time and transport-related physical activity domains of the IPAQ may be relevant for the Peruvian and similar low-resource contexts. First, the surveillance of physical activity can prioritize the utilization of the leisure and transport domains as a pragmatic approach. Second, the substantial low levels of physical activity reported in our study emphasize the immense window for improvement. In light of our findings, there is a clear need and opportunity to encourage leisure-time physical and transport-related physical activity, particularly in resource-constrained settings.

Our results suggest that increasing physical activity to levels associated with lower mortality risk seems to be achievable for any individual from the general population. As a matter of fact, to place these recommendations in perspective, improving physical activity could be achieved by walking for 30 minutes for 5 days at a usual pace ( 3 METs), or cycling 25 minutes for 6 days at a usual pace (3.5 METs) [31]. 
According to the Global Burden of Disease, worldwide, the implementation of appropriate interventions to change behaviors, especially those related to physical activity, diet quality, and caloric intake are limited by different challenges [6]. Strategies to encourage physical activity should target all age groups, and should be supportive, i.e., including friend, families, or even peers and professionals, and facilitate the access to indoor and outdoor recreation facilities [9]. In addition, such strategies should be implemented including the use of mobile technologies [32], but also improving the built environment to secure the safety of pedestrians and cyclists [33,34], which are common concerns in limited-resources settings.

\section{Strengths and limitations}

This study utilized information of a well-established cohort of participants across different settings in Peru, with high rates of follow-up and exploring a robust long-term outcome such as mortality, important features to inform relevant decision-making. In addition, our study used two domains of the IPAQ, rather than the full instrument, as previously recommended for Latin American settings [15]. We also provide longitudinal estimates of associations and providing a pragmatic low-cost way to support the NCD surveillance efforts.

However, there are some limitations that should be highlighted. First, physical activity was measured only at baseline and, therefore, changes in the patterns or profiles of physical activity over time were not considered and may affect the reported association. Despite this, establishing this association is of essence to support the wider NCD prevention agenda, particularly given mortality risks in a population understudied such as the Latin American region. Second, reverse causality may be present as some conditions before death may limit physical activity and we performed several sensitivity analyses excluding data of deaths occurred within the first 2 years of follow-up. Our sensitivity analyses results (Supplemental Tables 4 and 5) were consistent in direction and magnitude with our estimates herein reported as well as those previously published. Third, all-cause mortality was the outcome of interest, which is a robust indicator but does not allow for further exploration such as cardiovascular or cancer mortality, as that information was not available. Fourth, only two domains of the IPAQ were assessed and total physical activity was not available to be used as potential variable of control. Finally, some residual confounding may be present as variables associated with diet patterns were not available for this analysis.

\section{Conclusions}

Greater levels of leisure-time and transport-related physical activity, measured with the IPAQ were associated with a strong reduction in the risk of all-cause mortality across different geographical sites. These findings suggest the need to actively encourage leisure-time physical and transport-related physical activity in Peru and similar low-resource settings.

\section{REFERENCES}

1. Kyu HH, Bachman VF, Alexander LT, Mumford JE, Afshin A, Estep K, et al. Physical activity and risk of breast cancer, colon cancer, diabetes, ischemic heart disease, and ischemic stroke events: systematic review and dose-response meta-analysis for the Global Burden of Disease Study 2013. Bmj 2016;354:i3857.

2. Lee IM, Shiroma EJ, Lobelo F, Puska P, Blair SN, Katzmarzyk PT. Effect of physical inactivity on major non-communicable diseases worldwide: an analysis of burden of disease and life expectancy. Lancet 2012;380(9838):219-29.

3. Arem H, Moore SC, Patel A, Hartge P, Berrington de Gonzalez A, Visvanathan $\mathrm{K}$, et al. Leisure time physical activity and mortality: a detailed pooled analysis of the doseresponse relationship. JAMA Intern Med 2015;175(6):959-67.

4. Moore SC, Patel AV, Matthews CE, Berrington de Gonzalez A, Park Y, Katki HA, et al. Leisure time physical activity of moderate to vigorous intensity and mortality: a large pooled cohort analysis. PLoS Med 2012;9(11):e1001335. 
5. Blond K, Brinkløv CF, Ried-Larsen M, Crippa A, Grøntved A. Association of high amounts of physical activity with mortality risk: a systematic review and meta-analysis. Br J Sports Med 2020;54(20):1195-201.

6. GBD 2019 Risk Factors Collaborators. Global burden of 87 risk factors in 204 countries and territories, 1990-2019: a systematic analysis for the Global Burden of Disease Study 2019. Lancet 2020;396(10258):1223-49.

7. World Health Organization. Global action plan on physical activity 2018-2030: more active people for a healthier world. Geneva, Switzerland: WHO; 2018.

8. World Health Organization. Mid-point evaluation of the implementation of the WHO global action plan for the prevention and control of noncommunicable diseases 20132020 (NCD-GAP). Geneva, Switzerland: WHO; 2020.

9. US Department of Health and Human Resources. Physical Activity Guidelines for Americans, 2nd edition. Washington, DC: US Department of Health and Human Resources; 2018.

10. Katzmarzyk PT, Friedenreich C, Shiroma EJ, Lee IM. Physical inactivity and noncommunicable disease burden in low-income, middle-income and high-income countries. Br J Sports Med Published Online First: 29 March 2021;doi: 10.1136/bjsports2020-103640.

11. Dirección Ejecutiva de Vigilancia Alimentaria y Nutricional. Actividad física de adultos de 18 a 59 años - VIANEV 2017-2018. Lima, Peru: Centro Nacional de Alimentación y Nutrición, Instituto Naciona de Salud; 2020.

12. Miranda JJ, Carrillo-Larco RM, Gilman RH, Avilez JL, Smeeth L, Checkley W, et al. Patterns and Determinants of Physical Inactivity in Rural and Urban Areas in Peru: A Population-Based Study. J Phys Act Health 2016;13(6):654-62.

13. Beagle AJ, Tison GH, Aschbacher K, Olgin JE, Marcus GM, Pletcher MJ. Comparison of the Physical Activity Measured by a Consumer Wearable Activity Tracker and That Measured by Self-Report: Cross-Sectional Analysis of the Health eHeart Study. JMIR Mhealth Uhealth 2020;8(12):e22090.

14. Ferrari GLM, Kovalskys I, Fisberg M, Gómez G, Rigotti A, Sanabria LYC, et al. Comparison of self-report versus accelerometer - measured physical activity and sedentary behaviors and their association with body composition in Latin American countries. PLoS One 2020;15(4):e0232420.

15. Hallal PC, Gomez LF, Parra DC, Lobelo F, Mosquera J, Florindo AA, et al. Lessons learned after 10 years of IPAQ use in Brazil and Colombia. J Phys Act Health 2010;7 Suppl 2:S259-64.

16. Nocon M, Hiemann T, Müller-Riemenschneider F, Thalau F, Roll S, Willich SN. Association of physical activity with all-cause and cardiovascular mortality: a systematic review and meta-analysis. Eur J Cardiovasc Prev Rehabil 2008;15(3):239-46.

17. Lacombe J, Armstrong MEG, Wright FL, Foster $\mathrm{C}$. The impact of physical activity and an additional behavioural risk factor on cardiovascular disease, cancer and all-cause mortality: a systematic review. BMC Public Health 2019;19(1):900.

18. Miranda JJ, Bernabe-Ortiz A, Smeeth L, Gilman RH, Checkley W. Addressing geographical variation in the progression of non-communicable diseases in Peru: the CRONICAS cohort study protocol. BMJ Open 2012;2(1):e000610.

19. Lim SS, Vos T, Flaxman AD, Danaei G, Shibuya K, Adair-Rohani H, et al. A comparative risk assessment of burden of disease and injury attributable to 67 risk factors and risk factor clusters in 21 regions, 1990-2010: a systematic analysis for the Global Burden of Disease Study 2010. Lancet 2012;380(9859):2224-60.

20. Howe LD, Galobardes B, Matijasevich A, Gordon D, Johnston D, Onwujekwe O, et al. Measuring socio-economic position for epidemiological studies in low- and middleincome countries: a methods of measurement in epidemiology paper. Int $J$ Epidemiol 2012;41(3):871-86.

21. Morgan BW, Leifheit KM, Romero KM, Gilman RH, Bernabe-Ortiz A, Miranda JJ, et al. Low cigarette smoking prevalence in peri-urban Peru: results from a population-based study of tobacco use by self-report and urine cotinine. Tob Induc Dis 2017;15:32. 
22. Dawson DA. Methodological issues in measuring alcohol use. Alcohol Res Health 2003;27(1):18-29.

23. Chobanian AV, Bakris GL, Black HR, Cushman WC, Green LA, Izzo JL, Jr., et al. The Seventh Report of the Joint National Committee on Prevention, Detection, Evaluation, and Treatment of High Blood Pressure: the JNC 7 report. Jama 2003;289(19):2560-72.

24. American Diabetes Association. 2. Classification and Diagnosis of Diabetes: Standards of Medical Care in Diabetes-2021. Diabetes Care 2021;44(Suppl 1):S15-s33.

25. Jeong SW, Kim SH, Kang SH, Kim HJ, Yoon CH, Youn TJ, et al. Mortality reduction with physical activity in patients with and without cardiovascular disease. Eur Heart $J$ 2019;40(43):3547-55.

26. Ekelund U, Tarp J, Steene-Johannessen J, Hansen BH, Jefferis B, Fagerland MW, et al. Dose-response associations between accelerometry measured physical activity and sedentary time and all cause mortality: systematic review and harmonised metaanalysis. Bmj 2019;366:14570.

27. Kelly P, Kahlmeier S, Götschi T, Orsini N, Richards J, Roberts N, et al. Systematic review and meta-analysis of reduction in all-cause mortality from walking and cycling and shape of dose response relationship. Int J Behav Nutr Phys Act 2014;11:132.

28. Ku PW, Hamer M, Liao Y, Hsueh MC, Chen LJ. Device-measured light-intensity physical activity and mortality: A meta-analysis. Scand J Med Sci Sports 2020;30(1):1324.

29. Lear SA, Hu W, Rangarajan S, Gasevic D, Leong D, lqbal R, et al. The effect of physical activity on mortality and cardiovascular disease in 130000 people from 17 high-income, middle-income, and low-income countries: the PURE study. Lancet 2017;390(10113):2643-54.

30. Celis-Morales CA, Lyall DM, Welsh P, Anderson J, Steell L, Guo Y, et al. Association between active commuting and incident cardiovascular disease, cancer, and mortality: prospective cohort study. Bmj 2017;357:j1456.

31. American College of Sports Medicine. The Compendium of Physical Activities. ACSM Resource Manual 5th Edition; 2006.

32. Daryabeygi-Khotbehsara R, Shariful Islam SM, Dunstan D, McVicar J, Abdelrazek M, Maddison R. Smartphone-Based Interventions to Reduce Sedentary Behavior and Promote Physical Activity Using Integrated Dynamic Models: Systematic Review. J Med Internet Res 2021;23(9):e26315.

33. Quistberg DA, Koepsell TD, Miranda JJ, Ng Boyle L, Johnston BD, Ebel BE. The walking environment in Lima, Peru and pedestrian-motor vehicle collisions: an exploratory analysis. Traffic Inj Prev 2015;16(3):314-21.

34. Lo BK, Graham ML, Folta SC, Paul LC, Strogatz D, Nelson ME, et al. Examining the Associations between Walk Score, Perceived Built Environment, and Physical Activity Behaviors among Women Participating in a Community-Randomized Lifestyle Change Intervention Trial: Strong Hearts, Healthy Communities. Int J Environ Res Public Health 2019;16(5). 


\section{FIGURES AND TABLES}

Figure 1: All-cause mortality risk by physical activity levels: forest plot of adjusted models

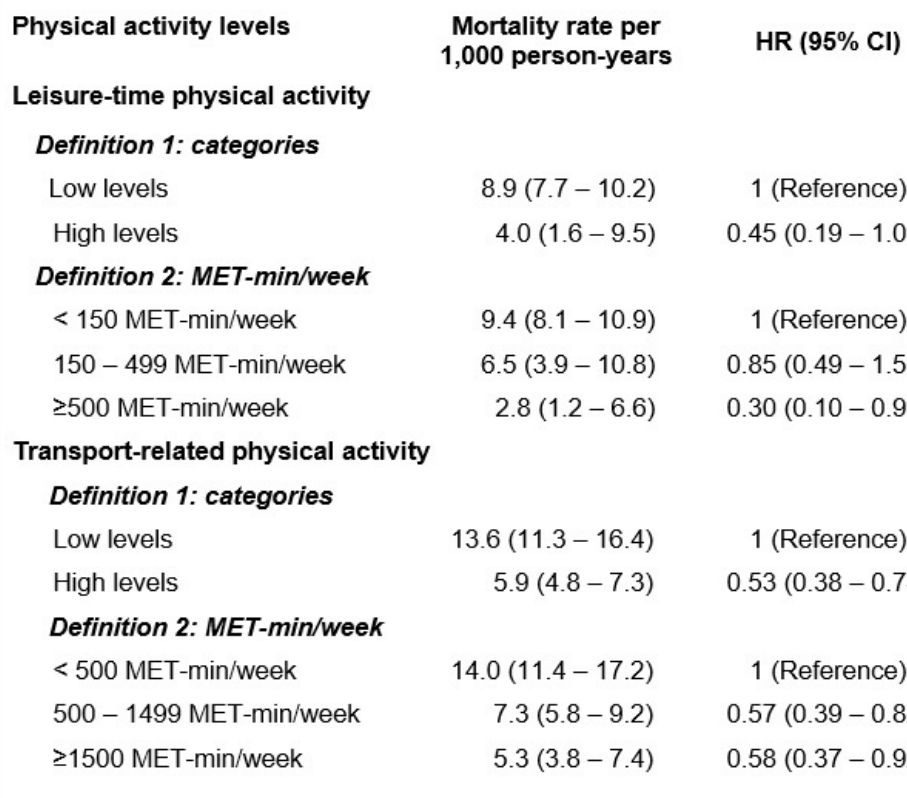

Mortality rate per 1,000 person-years

HR (95\% Cl)$$
5.3(3.8-7.4)
$$

$\mathrm{HR}=$ Hazard ratio.

Model adjusted by sex, age, years of education, socioeconomic position, study site, daily smoking, drinking, obesity, hypertension, total cholesterol, and type 2 diabetes status. 
Table 1: Characteristics of the study population by leisure-time physical activity

\begin{tabular}{|c|c|c|c|}
\hline \multirow{3}{*}{ Variables } & \multicolumn{2}{|c|}{ Leisure-time physical activity } & \multirow[b]{2}{*}{ p-value } \\
\hline & Moderate/high & Low & \\
\hline & $(n=185)$ & $(n=3406)$ & \\
\hline Sex & & & $<0.001$ \\
\hline Female & $59(3.2 \%)$ & 1787 (96.8\%) & \\
\hline Male & $126(7.2 \%)$ & $1615(92.8 \%)$ & \\
\hline Age & & & 0.02 \\
\hline $35-44$ years & $41(4.8 \%)$ & $816(95.2 \%)$ & \\
\hline $45-54$ years & $55(6.0 \%)$ & $866(94.0 \%)$ & \\
\hline $55-64$ years & $58(6.4 \%)$ & $854(93.6 \%)$ & \\
\hline $65+$ years & $31(3.5 \%)$ & $866(96.5 \%)$ & \\
\hline Years of education & & & $<0.001$ \\
\hline$<7$ years & $52(3.2 \%)$ & $1587(96.8 \%)$ & \\
\hline $7-11$ years & $54(4.7 \%)$ & $1101(95.3 \%)$ & \\
\hline $12+$ years & $79(9.9 \%)$ & $719(90.1 \%)$ & \\
\hline Socioeconomic position & & & $<0.001$ \\
\hline Low & $23(1.9 \%)$ & $1191(98.1 \%)$ & \\
\hline Middle & $59(5.0 \%)$ & $1125(95.0 \%)$ & \\
\hline High & $103(8.6 \%)$ & $1094(91.4 \%)$ & \\
\hline Study site & & & $<0.001$ \\
\hline Lima (highly urbanized) & $67(6.1 \%)$ & $1037(93.9 \%)$ & \\
\hline Urban Puno (urbanized) & $55(7.3 \%)$ & $704(92.7 \%)$ & \\
\hline Rural Puno (rural) & $16(2.3 \%)$ & $680(97.7 \%)$ & \\
\hline Tumbes (semiurban) & $47(4.6 \%)$ & $985(95.4 \%)$ & \\
\hline Daily smoking & & & 0.25 \\
\hline No & $182(5.2 \%)$ & $3299(94.8 \%)$ & \\
\hline Yes & $3(2.8 \%)$ & $106(97.3 \%)$ & \\
\hline Drinking & & & 0.04 \\
\hline Low & $169(5.0 \%)$ & $3231(95.0 \%)$ & \\
\hline High & $46(8.4 \%)$ & $175(91.6 \%)$ & \\
\hline Body mass index & & & 0.06 \\
\hline Normal & $47(5.0 \%)$ & 900 (95.0\%) & \\
\hline Overweight & $89(6.4 \%)$ & $1313(93.6 \%)$ & \\
\hline Obesity & $36(4.2 \%)$ & $831(95.9 \%)$ & \\
\hline Hypertension & & & 0.22 \\
\hline No & 135 (5.7\%) & 2247 (94.3\%) & \\
\hline Yes & $40(4.6 \%)$ & $836(95.4 \%)$ & \\
\hline Total cholesterol & & & 0.82 \\
\hline$<200 \mathrm{mg} / \mathrm{dL}$ & $87(5.3 \%)$ & $1567(94.7 \%)$ & \\
\hline $200-239 \mathrm{mg} / \mathrm{dL}$ & $53(5.5 \%)$ & $917(94.5 \%)$ & \\
\hline $240 \mathrm{mg} / \mathrm{dL}$ and over & $23(4.7 \%)$ & $468(95.3 \%)$ & \\
\hline Type 2 diabetes & & & 0.60 \\
\hline No & $147(5.2 \%)$ & $2710(94.8 \%)$ & \\
\hline Yes & $16(5.9 \%)$ & $256(94.1 \%)$ & \\
\hline
\end{tabular}

Comparisons were done using Chi-squared test. Percentages are in rows.

Low level of leisure time physical activity was defined as doing none or very little physical activity (i.e., <600 MET-min/week) during leisure time. 
Table 2: Characteristics of the study population by transport-related physical activity

\begin{tabular}{|c|c|c|c|}
\hline \multirow{3}{*}{ Variables } & \multicolumn{2}{|c|}{ Transport-related physical activity } & \multirow[b]{2}{*}{ p-value } \\
\hline & Moderate/high & Low & \\
\hline & $(n=2360)$ & $(n=1231)$ & \\
\hline Sex & & & $<0.001$ \\
\hline Female & $1067(57.8 \%)$ & $779(42.2 \%)$ & \\
\hline Male & $1289(74.0 \%)$ & $452(26.0 \%)$ & \\
\hline Age & & & $<0.001$ \\
\hline $35-44$ years & $602(70.3 \%)$ & $255(29.7 \%)$ & \\
\hline $45-54$ years & $667(72.4 \%)$ & $254(27.6 \%)$ & \\
\hline $55-64$ years & $617(67.7 \%)$ & $295(32.3 \%)$ & \\
\hline $65+$ years & $472(52.6 \%)$ & $425(47.4 \%)$ & \\
\hline Years of education & & & $<0.001$ \\
\hline$<7$ years & $903(55.1 \%)$ & $735(44.9 \%)$ & \\
\hline $7-11$ years & $824(71.5 \%)$ & $328(28.5 \%)$ & \\
\hline $12+$ years & $631(79.1 \%)$ & $167(20.9 \%)$ & \\
\hline Socioeconomic position & & & $<0.001$ \\
\hline Low & 709 (58.5\%) & $504(41.5 \%)$ & \\
\hline Middle & $770(65.1 \%)$ & $413(34.9 \%)$ & \\
\hline High & $881(73.7 \%)$ & $314(26.3 \%)$ & \\
\hline Study site & & & $<0.001$ \\
\hline Lima (highly urbanized) & $863(78.2 \%)$ & $241(21.8 \%)$ & \\
\hline Urban Puno (urbanized) & $571(75.2 \%)$ & $188(24.8 \%)$ & \\
\hline Rural Puno (rural) & $501(72.0 \%)$ & $195(28.0 \%)$ & \\
\hline Tumbes (semiurban) & $425(41.2 \%)$ & $607(58.8 \%)$ & \\
\hline Daily smoking & & & $<0.37$ \\
\hline No & $2283(65.6 \%)$ & $1198(34.2 \%)$ & \\
\hline Yes & $76(69.7 \%)$ & $33(30.3 \%)$ & \\
\hline Drinking & & & 0.006 \\
\hline Low & $2217(65.2 \%)$ & $1183(34.8 \%)$ & \\
\hline High & $143(74.9 \%)$ & $48(25.1 \%)$ & \\
\hline Body mass index & & & 0.10 \\
\hline Normal & 605 (63.9\%) & $342(36.1 \%)$ & \\
\hline Overweight & $935(66.7 \%)$ & 467 (33.3\%) & \\
\hline Obesity & $542(62.5 \%)$ & $325(37.5 \%)$ & \\
\hline Hypertension & & & $<0.001$ \\
\hline No & $1610(67.6 \%)$ & 772 (32.4\%) & \\
\hline Yes & $508(58.0 \%)$ & $368(42.0 \%)$ & \\
\hline Total cholesterol & & & 0.01 \\
\hline$<200 \mathrm{mg} / \mathrm{dL}$ & 1105 (66.8\%) & $549(33.2 \%)$ & \\
\hline $200-239 \mathrm{mg} / \mathrm{dL}$ & $598(61.7 \%)$ & $372(38.3 \%)$ & \\
\hline $240 \mathrm{mg} / \mathrm{dL}$ and over & $302(61.5 \%)$ & $189(38.5 \%)$ & \\
\hline Type 2 diabetes & & & 0.002 \\
\hline No & $1864(65.2 \%)$ & $993(34.8 \%)$ & \\
\hline Yes & $152(55.9 \%)$ & $120(44.1 \%)$ & \\
\hline
\end{tabular}

Comparisons were done using Chi-squared test. Percentages are in rows. Low level of transport-related physical activity was defined as not reporting walking or cycling trips in the transport domain of the IPAQ. 
SUPPLEMENTAL MATERIAL

Supplemental Table 1: Characteristics of the study population by level of physical activity

\begin{tabular}{|c|c|c|c|c|}
\hline \multirow[t]{2}{*}{ Variables } & $\begin{array}{c}\text { LTPA } \\
\text { (MET-min/week) }\end{array}$ & p-value & $\begin{array}{c}\text { TRPA } \\
\text { (MET-min/week) }\end{array}$ & p-value \\
\hline & Median (IQR) & & Median (IQR) & \\
\hline Sex & & $<0.001$ & & $<0.001$ \\
\hline Female & $0(0)$ & & $773(347-1333)$ & \\
\hline Male & $0(0-132)$ & & $1127(631-2062)$ & \\
\hline Age & & 0.009 & & $<0.001$ \\
\hline $35-44$ years & $0(0-40)$ & & $1026(565-1911)$ & \\
\hline $45-54$ years & $0(0-33)$ & & $1053(579-1975)$ & \\
\hline $55-64$ years & $0(0)$ & & $933(480-1813)$ & \\
\hline $65+$ years & $0(0)$ & & $693(297-1235)$ & \\
\hline Years of education & & $<0.001$ & & $<0.001$ \\
\hline$<7$ years & $0(0)$ & & $702(311-1253)$ & \\
\hline $7-11$ years & $0(0-33)$ & & $1049(582-1943)$ & \\
\hline $12+$ years & $0(0-198)$ & & $1180(702-2076)$ & \\
\hline \multicolumn{2}{|c|}{ Socioeconomic position } & $<0.001$ & & $<0.001$ \\
\hline Low & $0(0)$ & & $773(391-1315)$ & \\
\hline Middle & $0(0)$ & & $924(462-1680)$ & \\
\hline High & $0(0-160)$ & & $1120(622-2079)$ & \\
\hline Study site & & $<0.001$ & & $<0.001$ \\
\hline Lima & $0(0-99)$ & & $1318(693-2373)$ & \\
\hline Urban Puno & $0(0-99)$ & & $1071(640-1746)$ & \\
\hline Rural Puno & $0(0)$ & & $924(570-1464)$ & \\
\hline Tumbes & $0(0)$ & & $508(199-1013)$ & \\
\hline Daily smoking & & 0.29 & & 0.12 \\
\hline No & $0(0)$ & & $924(471-1676)$ & \\
\hline Yes & $0(0-80)$ & & $1191(499-2027)$ & \\
\hline Drinking & & 0.05 & & $<0.001$ \\
\hline Low & $0(0)$ & & $918(462-1663)$ & \\
\hline High & $0(0-99)$ & & $1235(640-2587)$ & \\
\hline Body mass index & & 0.04 & & 0.04 \\
\hline Normal & $0(0)$ & & $853(462-1516)$ & \\
\hline Overweight & $0(0-33)$ & & $954(480-1893)$ & \\
\hline Obesity & $0(0)$ & & $924(391-1653)$ & \\
\hline Hypertension & & 0.78 & & $<0.001$ \\
\hline No & $0(0)$ & & $942(499-1787)$ & \\
\hline Yes & $0(0)$ & & $775(323-1511)$ & \\
\hline \multicolumn{2}{|l|}{ High total cholesterol } & 0.62 & & 0.08 \\
\hline$<200 \mathrm{mg} / \mathrm{dL}$ & $0(0)$ & & $936(471-1795)$ & \\
\hline $240-239 \mathrm{mg} / \mathrm{dL}$ & $0(0-33)$ & & $853(405-1664)$ & \\
\hline $240 \mathrm{mg} / \mathrm{dL}$ and over & $0(0)$ & & $876(405-1582)$ & \\
\hline Type 2 diabetes & & 0.88 & & 0.01 \\
\hline No & $0(0)$ & & $933(462-1737)$ & \\
\hline Yes & $0(0)$ & & $782(323-1409)$ & \\
\hline
\end{tabular}

Comparisons were done using the nonparametric equality-of-medians test. 
Supplemental Table 2: Characteristics of the study population by leisure-time physical activity

\begin{tabular}{|c|c|c|c|c|}
\hline \multirow{3}{*}{ Variables } & \multicolumn{3}{|c|}{ Leisure-time physical activity } & \multirow[b]{2}{*}{ p-value } \\
\hline & $\begin{array}{l}<150 \text { MET- } \\
\mathrm{min} / \text { week }\end{array}$ & $\begin{array}{c}\text { 150-499 MET- } \\
\mathrm{min} / \text { week }\end{array}$ & $\begin{array}{l}\text { 500+ MET- } \\
\mathrm{min} / \text { week }\end{array}$ & \\
\hline & $(n=2982)$ & $(n=337)$ & $(n=268)$ & \\
\hline Sex & & & & $<0.001$ \\
\hline Female & $1656(55.5 \%)$ & $109(32.3 \%)$ & $81(30.2 \%)$ & \\
\hline Male & $1326(44.5 \%)$ & $228(67.7 \%)$ & $187(69.8 \%)$ & \\
\hline Age & & & & 0.005 \\
\hline $35-44$ years & $694(23.3 \%)$ & $94(27.9 \%)$ & $69(25.8 \%)$ & \\
\hline $45-54$ years & $748(25.1 \%)$ & $90(26.7 \%)$ & $83(31.0 \%)$ & \\
\hline $55-64$ years & $763(25.6 \%)$ & $76(22.6 \%)$ & $73(27.2 \%)$ & \\
\hline $65+$ years & $777(26.0 \%)$ & $77(22.8 \%)$ & $43(16.0 \%)$ & \\
\hline Years of education & & & & $<0.001$ \\
\hline$<7$ years & $1462(49.0 \%)$ & $107(31.8 \%)$ & $69(25.8 \%)$ & \\
\hline $7-11$ years & $947(31.8 \%)$ & $122(36.2 \%)$ & $83(31.0 \%)$ & \\
\hline $12+$ years & $574(19.2 \%)$ & $108(32.0 \%)$ & $116(43.2 \%)$ & \\
\hline Socioeconomic position & & & & $<0.001$ \\
\hline Low & $1095(36.7 \%)$ & $81(24.0 \%)$ & $37(13.8 \%)$ & \\
\hline Middle & $996(33.4 \%)$ & $103(30.6 \%)$ & $84(31.3 \%)$ & \\
\hline High & $895(29.9 \%)$ & $153(45.4 \%)$ & $147(54.9 \%)$ & \\
\hline Study site & & & & $<0.001$ \\
\hline Lima (highly urbanized) & $875(29.3 \%)$ & $134(39.8 \%)$ & $95(35.5 \%)$ & \\
\hline Urban Puno (urbanized) & $592(19.8 \%)$ & $86(25.5 \%)$ & $81(30.2 \%)$ & \\
\hline Rural Puno (rural) & $638(21.4 \%)$ & $30(8.9 \%)$ & $28(10.5 \%)$ & \\
\hline Tumbes (semiurban) & $881(29.5 \%)$ & $87(25.8 \%)$ & $64(23.8 \%)$ & \\
\hline Daily smoking & & & & 0.07 \\
\hline No & $2899(97.1 \%)$ & $320(95.0 \%)$ & $262(97.8 \%)$ & \\
\hline Yes & $86(2.9 \%)$ & $17(5.0 \%)$ & $6(2.2 \%)$ & \\
\hline Drinking & & & & 0.09 \\
\hline Low & $2838(95.0 \%)$ & $314(93.2 \%)$ & $248(92.5 \%)$ & \\
\hline High & $148(5.0 \%)$ & $23(6.8 \%)$ & $20(7.5 \%)$ & \\
\hline Body mass index & & & & 0.17 \\
\hline Normal & $788(29.6 \%)$ & $87(28.7 \%)$ & $72(29.3 \%)$ & \\
\hline Overweight & $1146(43.0 \%)$ & $133(43.9 \%)$ & $123(50.0 \%)$ & \\
\hline Obesity & $733(27.5 \%)$ & $83(27.4 \%)$ & $51(20.7 \%)$ & \\
\hline Hypertension & & & & 0.06 \\
\hline No & 1969 (72.9\%) & $216(70.1 \%)$ & $197(78.8 \%)$ & \\
\hline Yes & $731(27.1 \%)$ & $92(29.9 \%)$ & $53(21.2 \%)$ & \\
\hline High total cholesterol & & & & 0.94 \\
\hline$<200 \mathrm{mg} / \mathrm{dL}$ & $1367(52.9 \%)$ & $157(52.9 \%)$ & $130(55.3 \%)$ & \\
\hline $240-239 \mathrm{mg} / \mathrm{dL}$ & $804(31.1 \%)$ & $94(31.6 \%)$ & $72(30.7 \%)$ & \\
\hline $240 \mathrm{mg} / \mathrm{dL}$ and over & $412(16.0 \%)$ & $46(15.5 \%)$ & $33(14.0 \%)$ & \\
\hline Type 2 diabetes & & & & 0.91 \\
\hline No & $2370(91.4 \%)$ & $271(90.6 \%)$ & $216(91.5 \%)$ & \\
\hline Yes & $224(8.6 \%)$ & $28(9.4 \%)$ & 20 (8.5\%) & \\
\hline
\end{tabular}

Comparisons were done using Chi-squared test. 
Supplemental Table 3: Characteristics of the study population by transport-related physical activity

\begin{tabular}{|c|c|c|c|c|}
\hline \multirow{3}{*}{ Variables } & \multicolumn{3}{|c|}{ Transport-related physical activity } & \multirow[b]{2}{*}{ p-value } \\
\hline & $\begin{array}{l}<500 \text { MET- } \\
\text { min/week }\end{array}$ & $\begin{array}{l}\text { 500-1499 MET- } \\
\text { min/week }\end{array}$ & $\begin{array}{c}\text { 1500+ MET- } \\
\text { min/week }\end{array}$ & \\
\hline & $(n=2982)$ & $(n=337)$ & $(n=268)$ & \\
\hline Sex & & & & $<0.001$ \\
\hline Female & $630(64.4 \%)$ & $820(52.3 \%)$ & $396(38.0 \%)$ & \\
\hline Male & $348(35.6 \%)$ & $747(47.7 \%)$ & $646(62.0 \%)$ & \\
\hline Age & & & & $<0.001$ \\
\hline $35-44$ years & $184(18.8 \%)$ & $376(24.0 \%)$ & $297(28.5 \%)$ & \\
\hline $45-54$ years & $201(20.6 \%)$ & $412(26.3 \%)$ & $308(29.5 \%)$ & \\
\hline $55-64$ years & $238(24.4 \%)$ & $397(25.4 \%)$ & $277(26.5 \%)$ & \\
\hline $65+$ years & $354(36.2 \%)$ & $381(24.3 \%)$ & $162(15.5 \%)$ & \\
\hline Years of education & & & & $<0.001$ \\
\hline$<7$ years & $602(61.5 \%)$ & $712(45.4 \%)$ & $324(31.1 \%)$ & \\
\hline $7-11$ years & $252(25.8 \%)$ & $496(31.7 \%)$ & $404(38.7 \%)$ & \\
\hline $12+$ years & $124(12.7 \%)$ & $359(22.9 \%)$ & $315(30.2 \%)$ & \\
\hline Socioeconomic position & & & & $<0.001$ \\
\hline Low & $405(41.4 \%)$ & $562(35.8 \%)$ & $246(23.6 \%)$ & \\
\hline Middle & $328(33.5 \%)$ & $511(32.6 \%)$ & $344(32.9 \%)$ & \\
\hline High & $245(25.1 \%)$ & $496(31.6 \%)$ & $454(43.5 \%)$ & \\
\hline Study site & & & & $<0.001$ \\
\hline Lima (highly urbanized) & $187(19.1 \%)$ & $431(27.4 \%)$ & $486(46.5 \%)$ & \\
\hline Urban Puno (urbanized) & $148(15.1 \%)$ & $367(23.4 \%)$ & $244(23.4 \%)$ & \\
\hline Rural Puno (rural) & $133(13.6 \%)$ & $395(25.2 \%)$ & $168(16.1 \%)$ & \\
\hline Tumbes (semiurban) & $510(52.2 \%)$ & $376(24.0 \%)$ & $146(14.0 \%)$ & \\
\hline Daily smoking & & & & 0.12 \\
\hline No & $950(97.1 \%)$ & $1528(97.5 \%)$ & $1003(96.1 \%)$ & \\
\hline Yes & $28(2.9 \%)$ & $40(2.5 \%)$ & $41(3.9 \%)$ & \\
\hline Drinking & & & & $<0.001$ \\
\hline Low & $942(96.3 \%)$ & $1496(95.4 \%)$ & $962(92.2 \%)$ & \\
\hline High & $36(3.7 \%)$ & $73(4.7 \%)$ & $82(7.9 \%)$ & \\
\hline Body mass index & & & & 0.002 \\
\hline Normal & $284(31.2 \%)$ & $423(30.9 \%)$ & $240(25.6 \%)$ & \\
\hline Overweight & $362(39.8 \%)$ & $585(42.8 \%)$ & $455(48.5 \%)$ & \\
\hline Obesity & $264(29.0 \%)$ & $359(26.3 \%)$ & $244(25.9 \%)$ & \\
\hline Hypertension & & & & $<0.001$ \\
\hline No & $602(65.8 \%)$ & $1050(75.4 \%)$ & $730(76.8 \%)$ & \\
\hline Yes & $313(34.2 \%)$ & $342(24.6 \%)$ & $221(23.2 \%)$ & \\
\hline High total cholesterol & & & & 0.02 \\
\hline$<200 \mathrm{mg} / \mathrm{dL}$ & $441(49.3 \%)$ & $702(53.7 \%)$ & $511(56.0 \%)$ & \\
\hline $240-239 \mathrm{mg} / \mathrm{dL}$ & $308(34.5 \%)$ & $386(29.5 \%)$ & $276(30.2 \%)$ & \\
\hline $240 \mathrm{mg} / \mathrm{dL}$ and over & $145(16.2 \%)$ & $220(16.8 \%)$ & $126(13.8 \%)$ & \\
\hline Type 2 diabetes & & & & 0.02 \\
\hline No & $800(89.3 \%)$ & $1201(91.5 \%)$ & $856(93.0 \%)$ & \\
\hline Yes & $96(10.7 \%)$ & $112(8.5 \%)$ & $64(7.0 \%)$ & \\
\hline
\end{tabular}

Comparisons were done using Chi-squared test. 
Supplemental Table 4: All-cause mortality risk by physical activity levels: crude and adjusted models

\begin{tabular}{|c|c|c|c|}
\hline & $\begin{array}{l}\text { Mortality rate } \\
(95 \% \mathrm{Cl})\end{array}$ & $\begin{array}{l}\text { Crude model } \\
\text { HR }(95 \% \mathrm{Cl})\end{array}$ & $\frac{\text { Adjusted model }^{*}}{\mathrm{HR}(95 \% \mathrm{Cl})}$ \\
\hline \multicolumn{4}{|l|}{ Leisure-time physical activity } \\
\hline \multicolumn{4}{|l|}{ Definition 1: categories } \\
\hline Low level & $8.9(7.7-10.2)$ & 1 (Ref) & 1 (Ref) \\
\hline High level & $4.0(1.6-9.5)$ & $0.45(0.19-1.09)$ & $0.45(0.14-1.41)$ \\
\hline \multicolumn{4}{|l|}{ Definition 2: MET-min/week } \\
\hline$<150$ MET-min/week & $9.4(8.1-10.9)$ & 1 (Ref) & 1 (Ref) \\
\hline 150 - 499 MET-min/week & $6.5(3.9-10.8)$ & $0.69(0.41-1.18)$ & $0.85(0.49-1.50)$ \\
\hline$\geq 500 \mathrm{MET}-\mathrm{min} /$ week & $2.8(1.2-6.6)$ & $0.30(0.12-0.72)$ & $0.30(0.10-0.97)$ \\
\hline \multicolumn{4}{|c|}{ Transport-related physical activity } \\
\hline \multicolumn{4}{|l|}{ Definition 1: categories } \\
\hline Low level & $13.6(11.3-16.4)$ & 1 (Ref) & 1 (Ref) \\
\hline High level & $5.9(4.8-7.3)$ & $0.43(0.32-0.57)$ & $0.53(0.38-0.74)$ \\
\hline \multicolumn{4}{|l|}{ Definition 2: MET-min/week } \\
\hline$<500 \mathrm{MET}$-min/week & $14.0(11.4-17.2)$ & 1 (Ref) & 1 (Ref) \\
\hline 500 - 1499 MET-min/week & $7.3(5.8-9.2)$ & $0.52(0.38-0.71)$ & $0.57(0.39-0.82)$ \\
\hline$\geq 1500 \mathrm{MET}-\mathrm{min} /$ week & $5.3(3.8-7.4)$ & $0.37(0.25-0.55)$ & $0.58(0.37-0.92)$ \\
\hline
\end{tabular}

Mortality rate was calculated by 1000 person-years of follow-up. Bold estimates are significant $(p<0.05)$.

Low level of leisure time physical activity was defined as doing none or very little physical activity (i.e., <600 MET$\mathrm{min} /$ week) during leisure time. Low level of transport-related physical activity was defined as not reporting walking or cycling trips in the transport domain of the IPAQ.

* Model adjusted by sex, age, years of education, socioeconomic position, study site, daily smoking, drinking, obesity, hypertension, total cholesterol, and type 2 diabetes status. 
Supplemental Table 5: All-cause mortality risk by leisure-time physical activity: sensitivity analysis

\begin{tabular}{|c|c|c|c|}
\hline & $\begin{array}{c}\text { Mortality rate } \\
(95 \% \mathrm{Cl})\end{array}$ & $\begin{array}{l}\text { Crude model } \\
\mathrm{HR}(95 \% \mathrm{Cl}) \\
\end{array}$ & $\begin{array}{c}\text { Adjusted model }^{\star} \\
\text { HR }(95 \% \mathrm{Cl})\end{array}$ \\
\hline \multicolumn{4}{|c|}{ Excluding deaths occurring within first 2 years of follow-up } \\
\hline \multicolumn{4}{|l|}{ Definition 1: } \\
\hline Low level & $7.0(5.9-8.2)$ & 1 (Ref) & 1 (Ref) \\
\hline High level & $1.6(0.4-6.4)$ & $0.23(0.06-0.92)$ & $0.36(0.09-1.46)$ \\
\hline \multicolumn{4}{|l|}{ Definition 2: } \\
\hline$<150 \mathrm{MET}-\mathrm{min} /$ week & $7.4(6.3-8.7)$ & 1 (Ref) & 1 (Ref) \\
\hline 150 - 499 MET-min/week & $4.8(2.6-8.6)$ & $0.64(0.35-1.19)$ & $0.77(0.41-1.46)$ \\
\hline$\geq 500 \mathrm{MET}-\mathrm{min} /$ week & $1.1(0.3-4.4)$ & $0.15(0.04-0.60)$ & $0.24(0.06-0.98)$ \\
\hline \multicolumn{4}{|c|}{ Excluding hypertension and type 2 diabetes cases at baseline } \\
\hline \multicolumn{4}{|l|}{ Definition 1: } \\
\hline Low level & $8.1(7.0-9.4)$ & 1 (Ref) & 1 (Ref) \\
\hline High level & $6.6(5.5-7.9)$ & $0.30(0.10-0.94)$ & $0.17(0.02-1.20)$ \\
\hline \multicolumn{4}{|l|}{ Definition 2: } \\
\hline$<150$ MET-min/week & $8.2(7.0-9.5)$ & 1 (Ref) & 1 (Ref) \\
\hline $150-499$ MET-min/week & $6.7(5.6-8.0)$ & $0.66(0.38-1.17)$ & $0.88(0.48-1.61)$ \\
\hline$\geq 500 \mathrm{MET}-\mathrm{min} /$ week & $6.6(5.5-7.9)$ & $0.20(0.06-0.61)$ & $0.11(0.02-0.79)$ \\
\hline \multicolumn{4}{|c|}{ Comparing those who reported no LTPA vs any LTPA } \\
\hline No LTPA & $7.5(6.3-8.9)$ & 1 (Ref) & 1 (Ref) \\
\hline Any LTPA & $4.2(2.8-6.3)$ & $0.56(0.36-0.87)$ & $0.64(0.39-1.04)$ \\
\hline \multicolumn{4}{|c|}{ Using 500-MET-min/week as cutoff } \\
\hline$<500$ MET-min/week & $7.1(6.1-8.4)$ & 1 (Ref) & 1 (Ref) \\
\hline$\geq 500$ MET-min/week & $1.1(0.3-4.4)$ & $0.16(0.04-0.63)$ & $0.25(0.06-1.01)$ \\
\hline
\end{tabular}

LTPA = Leisure-time physical activity. Mortality rate was calculated by 1000 person-years of follow-up. Bold estimates are significant $(p<0.05)$. Models were built using deaths occurring after 2 years of follow-up.

* Model adjusted by sex, age, years of education, socioeconomic position, study site, daily smoking, drinking, obesity, hypertension, total cholesterol, and type 2 diabetes status, except for the case when hypertension and type 2 diabetes cases were excluded at baseline. 
Supplemental Table 6: All-cause mortality risk by transport-related physical activity: sensitivity analysis

\begin{tabular}{|c|c|c|c|}
\hline & $\begin{array}{c}\text { Mortality rate } \\
(95 \% \mathrm{Cl})\end{array}$ & $\begin{array}{l}\text { Crude model } \\
\text { HR (95\% Cl) }\end{array}$ & $\begin{array}{c}\text { Adjusted model* } \\
\text { HR }(95 \% \mathrm{Cl})\end{array}$ \\
\hline \multicolumn{4}{|c|}{ Excluding deaths occurring within first 2 years of follow-up } \\
\hline \multicolumn{4}{|l|}{ Definition 1: } \\
\hline Low level & $11.0(8.9-13.6)$ & 1 (Ref) & 1 (Ref) \\
\hline High level & $4.4(3.4-5.6)$ & $0.39(0.28-0.53)$ & $0.50(0.34-0.74)$ \\
\hline \multicolumn{4}{|l|}{ Definition 2: } \\
\hline$<500$ MET-min/week & $11.4(9.0-14.3)$ & 1 (Ref) & 1 (Ref) \\
\hline 500 - 1499 MET-min/week & $5.4(4.2-7.1)$ & $0.47(0.33-0.67)$ & $0.58(0.38-0.89)$ \\
\hline$\geq 1500 \mathrm{MET}-\mathrm{min} /$ week & $4.0(2.7-5.8)$ & $0.34(0.22-0.53)$ & $0.59(0.35-0.98)$ \\
\hline \multicolumn{4}{|c|}{ Excluding hypertension and type 2 diabetes cases at baseline } \\
\hline \multicolumn{4}{|c|}{ Definition 1: } \\
\hline Low level & $8.3(7.1-9.7)$ & 1 (Ref) & 1 (Ref) \\
\hline High level & $6.6(5.6-7.9)$ & $0.42(0.31-0.56)$ & $0.52(0.36-0.74)$ \\
\hline \multicolumn{4}{|l|}{ Definition 2: } \\
\hline$<500$ MET-min/week & $8.0(6.9-9.4)$ & 1 (Ref) & 1 (Ref) \\
\hline 500 - 1499 MET-min/week & $7.0(5.9-8.3)$ & $0.50(0.36-0.70)$ & $0.54(0.36-0.80)$ \\
\hline$\geq 1500 \mathrm{MET}-\mathrm{min} /$ week & $6.6(5.6-7.9)$ & $0.37(0.25-0.55)$ & $0.54(0.33-0.87)$ \\
\hline \multicolumn{4}{|c|}{ Comparing those who reported no TRPA vs any TRPA } \\
\hline No TRPA & $32.6(22.0-48.3)$ & 1 (Ref) & 1 (Ref) \\
\hline Any TRPA & $5.8(4.9-6.9)$ & $0.17(0.11-0.26)$ & $0.27(0.16-0.43)$ \\
\hline \multicolumn{4}{|c|}{ Using 500-MET-min/week as cutoff } \\
\hline$<500$ MET-min/week & $11.4(9.0-14.3)$ & 1 (Ref) & 1 (Ref) \\
\hline$\geq 500 \mathrm{MET}-\mathrm{min} /$ week & $4.9(3.9-6.0)$ & $0.42(0.31-0.58)$ & $0.57(0.39-0.84)$ \\
\hline
\end{tabular}

TRPA = Transport-related physical activity. Mortality rate was calculated by 1000 person-years of follow-up. Bold estimates are significant $(p<0.05)$. Models were built using deaths occurring after 2 years of follow-up.

* Model adjusted by sex, age, years of education, socioeconomic position, study site, daily smoking, drinking, obesity, hypertension, total cholesterol, and type 2 diabetes status, except for the case when hypertension and type 2 diabetes cases were excluded at baseline. 